\title{
Human African Trypanosomiasis Successfully Treated with Melarsoprol in Pregnancy in a Niger Delta Rural Hospital
}

\author{
Uchechukwu C. Ugoji1 ${ }^{*}$, Andrew A. Bock-Oruma1, Duncan Umukoro², \\ Geraldine U. Ndukwu ${ }^{3}$ \\ ${ }^{1}$ Department of Family Medicine, Shawsand Medical Centre, Port Harcourt, Nigeria \\ ${ }^{2}$ Department of Family Medicine, Delta State University, Abraka, Nigeria \\ ${ }^{3}$ Department of Family Medicine, University of Port Harcourt Teaching Hospital, Port Harcourt, Nigeria \\ Email: uchematters2@yahoo.com, bockoruma@yahoo.com, dunflox@gmail.com, gndukwu@yahoo.com
}

Received 8 April 2014; revised 7 May 2014; accepted 6 June 2014

Copyright (C) 2014 by authors and Scientific Research Publishing Inc.

This work is licensed under the Creative Commons Attribution International License (CC BY). http://creativecommons.org/licenses/by/4.0/

c) (i) Open Access

\begin{abstract}
Human African trypanosomiasis (HAT) commonly known as sleeping sickness occurs in about 36 countries in sub-Saharan Africa and results in a large number of deaths and considerable illness. The drugs used in the treatment of HAT are very toxic and therefore might not be safe in pregnancy. Few published data exist on the treatment of HAT in pregnancy. We describe a case of $T$. brucei gambiense infection occurring in a pregnant woman that was successfully treated with Melarsoprol with no toxic effect to mother and the baby after 2 years of follow-up.
\end{abstract}

\section{Keywords}

African Trypanosomiasis, Sub-Saharan Africa, Pregnancy, Melarsoprol

\section{Introduction}

Human African trypanosomiasis has been identified as the third most important contributor to the global burden of parasitic diseases after malaria and schistosomiasis [1]. According to WHO, it is the deadliest disease in the world [2]. HAT is an illness endemic to sub-Saharan Africa extending to about $14^{\circ} \mathrm{N}$ and $20^{\circ} \mathrm{S}$ [2] [3]. It is distinct from American trypanosomiasis, which is caused by Trypanosoma cruzi, and has different vectors, clinical manifestations, and therapies [4]. Epidemics of sleeping sickness have been a significant public health problem

\footnotetext{
*Corresponding author.
}

How to cite this paper: Ugoji, U.C., Bock-Oruma, A.A., Umukoro, D. and Ndukwu, G.U. (2014) Human African Trypanosomiasis Successfully Treated with Melarsoprol in Pregnancy in a Niger Delta Rural Hospital. Case Reports in Clinical Medicine, 3, 353-356. http://dx.doi.org/10.4236/crcm.2014.36078 
in the past, but the disease is reasonably well-controlled at present. In 2009, the number of reported cases from all 36 sub-Saharan African countries affected was put at less than 10,000 as against 40,000 in 1998 [2] [5]. However, it is believed that many cases go undiagnosed and unreported [5]. HAT is caused by the flagellate protozoan, Trypanosoma brucei, which exists in 2 morphologically identical subspecies; Trypanosoma brucei rhodesiense and Trypanosoma brucei gambiense [5]. Trypanosoma brucei is transmitted to human hosts by bites of infected tsetse flies (Glossina species), which are found only in Africa. Unlike other victors, Tsetse flies bite during daylight hours, both male and female flies can transmit the infection during a blood meal [2] [3] [5]. Although the vast majority of infections are transmitted by the tsetse fly, other modes of transmission are possible. Occasionally, a pregnant woman can pass the infection to her unborn baby. In theory, the infection can also be transmitted by blood transfusion; accidental infections in laboratories due to pricks from contaminated needles or sexual contact, but such cases have rarely been documented [1] [2] [5] [6]. The disease can be categorized geographically into West and East African trypanosomiasis. T. b. rhodesiense (East African sleeping sickness) is found in focal areas of eastern and southeastern Africa whereas T. b. gambiense (West African sleeping sickness) is found predominantly in central Africa and in limited areas of West Africa [5]-[7]. The West African form of the disease is more common than the East African form and accounts for 95\% of the global incidence of trypanosomiasis [3] [7]. The reservoir of infection for T. b. gambiense is exclusively human but for T. b. rhodesiense is animals especially cattle. Cattle have been implicated in the spread of the disease to new areas and in local outbreaks. A wild animal reservoir is thought to be responsible for sporadic transmission to hunters and visitors to game parks [5]-[8]. HAT can also be classified based on clinico-pathologic features into hemolymphatic (stage I) disease and meningoencephalitic (stage II) disease [9]. Most of the drugs used for the treatment of HAT especially the second stage of the disease have been reported to result in severe adverse reaction in the patient which can sometimes be fatal. It is also known that most of these drugs are not safe in pregnancy [1] [5]. We hereby present a case of HAT in a pregnant woman at the second stage of the disease that is successfully treated with Melarsoprol without adverse effect on the mother and the fetus.

\section{Case Presentation}

A twenty three year old multiparous woman from a rural community in the Niger delta of Nigeria was booked at eight weeks of gestational age and returned two weeks later with a two-month history of progressively worsening excessive sleepiness associated with obtundation of the senses and weakness. The patient's three year old child had been treated three months earlier for trypanosomiasis in the same hospital. Physical examination of the gravid patient revealed a drowsy woman with no palpable cervical lymph node, a temperature of $38.40^{\circ} \mathrm{C}$, and BP of 70/60. CSF analysis revealed flagellated trypanosomes. Full blood count was normal except for a PCV of $29 \%$ with a normocytic, hypochromic blood picture. A definitive diagnosis of trypanosomiasis with CNS manifestation (Stage II trypanosomiasis) was made and the patient subsequently admitted. The following day on admission her BP dropped to 70/50 mmHg for which she had two litres of normal saline bolus. She had her first course of melarsoprol with prednisolone after an informed consent was obtained and signed. The patient improved and was discharged home after 8 days on admission. She completed the second and third courses of melarsoprol at the outpatient. The patient was followed closely at the antenatal clinic by the obstetrician until she delivered a full term, live normal baby with no identifiable congenital anomaly. Two years later mother and child continued to remain in good health with no neurologic sequelae.

\section{Discussion}

Human African trypanosomiasis or sleeping sickness is a widespread tropical disease that can be fatal if not treated [5] [10]. In the first stage of the disease, the parasite is found in the peripheral circulation without invading the central nervous system. The symptoms of African trypansomiasis at this stage which depends on the host and the sub-species of trypanosome are mostly generalized pain, weakness, cramps and swelling of neck lymph nodes (Winterbottom's sign) [11]. The parasites can invade all organs of the body including heart and CNS. Once the parasite crosses the blood-brain barrier and infects the central nervous system, the disease enters the second stage. This leads to apathy, mental dullness, tremors, convulsions and sleepiness, coma. If left untreated at this stage there is rapid weight loss and death in a few months later [1] [2] [5]. Trypanosoma brucei rhodesiense (T.b.r.) causes an acute infection. First signs and symptoms are observed a few months or weeks after infection. The disease develops rapidly and invades the central nervous system, unlike Trypanosoma brucei gam- 
biense (T.b.g.) which causes a chronic infection. A person can be infected for months or even years without major signs or symptoms of the disease. When symptoms emerge, the patient is often already in an advanced disease stage where the central nervous system is affected [2]-[5]. This was the case with the index patient who presented with symptoms and signs of stage II disease.

The definitive diagnosis and staging of African Trypanosomiasis is made through laboratory methods which rests on finding the parasite in body fluid or tissue by microscopy [5] [11]. Trypanosomes can often be observed in cerebrospinal fluid in persons with second stage infection which was the case with the index patient. According to The World Health Organization, the criteria for central nervous system involvement include increased protein in cerebrospinal fluid and a white cell count of more than 5 [2] [5]. Other abnormalities associated with African trypanosomiasis include anaemia, hypergammaglobulinemia, elevated ESR, thrombocytopenia, and hypoalbuminemia, but not eosinophilia or abnormal liver function [2] [5] [11]. The index patient presents with a PCV of $29 \%$ which suggestive of mild anaemia.

Stage II HAT in pregnancy is fatal and may result in abortions, premature delivery, still birth and perinatal death [12]-[14]. In a study involving 76 women of childbearing age with HAT observation over a period of 13 months, four women who were pregnant had complications such as hydramnios, preeclampsia, abortion, stillbirth, and premature birth in an [13]. In a similar study among 160 women of childbearing age infected with T.b. gambiense, Sina et al. reported that among the 17 pregnant women, ten had abortions and seven normal pregnancies [14].

The treatment of stage II disease in pregnancy is problematic as there is no available guide in the literature and if left untreated, the disease is fatal. However, the drug of choice for the treatment of this stage II disease in all categories of persons is melarsoprol [2] [7]-[10]. The use of melarsoprol in pregnancy carries a lot of concern not only for the mother but also the fetus [13] [14]. Post treatment encephalopathy is known to occur in about $10 \%$ of cases, often causing death [15]. It is for the above reasons that pentamidine (for T. gambiense) or suramin (for T. rhodesian) are recommended for the treatment of stage II trypanosomiasis while melarsoprol use must be deferred until immediately after pregnancy [16]. In our patient this recommendation was not practical as the patient came in a bad shape that necessitated treatment with the only available drug, melarsoprol. This case like other successfully treated HAT in pregnancy demonstrates the need for a review of current recommendation on melarsoprol use in pregnancy [13] [17]. The World health organization (WHO) in April, 2009, approved the combination of Nifurtimox and eflornithine for use in the treatment of stage II HAT [16]. This regimen, although not presently available in our country, is believed to have the advantage of not only being less toxic but also available orally. No doubt this regimen will cut down greatly on the cost of treating HAT as it does not impose mandatory admission as is the case with melarsoprol. Fetal transmission of T. gambiense although well documented rarely occurs [17] [18]. Comparably, maternal-fetal transmission of parasites occurs in 5\% - 6\% of mothers infected with $T$. cruzi [4].

There is no test of cure for African trypanosomiasis. Patients should be followed with a lumbar puncture every 6 months (or sooner, if symptoms return) for 2 years after treatment to detect a relapse should it occur.

The long, relatively asymptomatic first stage of $T$. $b$. gambiense sleeping sickness is one of the reasons why an exhaustive, active screening of the population at risk is required, in order to identify patients at an early stage and reduce transmission. Exhaustive screenings require a major investment in human and material resources. In Africa such resources are often scarce, particularly in remote areas where the disease is mostly found. As a result, many infected individuals may die before they can ever be diagnosed and treated.

This patient was managed in Eku Baptist Hospital in Delta state, the only state where transmission is reportedly currently occurring in Nigeria, specifically the Abraka focus [7].

\section{Conclusion}

The treatment of HAT in pregnancy is problematic as there is no available guide in the literature and if left untreated, the disease is fatal. Despite the potential toxicity of melasoprol in pregnancy, it was used successfully in this case. However, a review of the medical treatment of HAT in pregnancy in resource-poor setting is advocated.

\section{Ethical Issues}

Necessary permission was obtained before this case was written for publication. 


\section{References}

[1] Tietze, P.E. and Jones, J.E. (1991) Parasites during Pregnancy. Primary Care, 18, 75-99.

[2] World Health Organization (2010) WHO Factsheet No. 259 African Trypanosomiasis.

[3] Edeghere, H., Olise, P.O. and Olatunde, D.S. (1989) Human African Trypanosomiasis (Sleeping Sickness): New Endemic Foci in Bendel State, Nigeria. Annals of Tropical Medicine and Parasitology, 40, 16-20.

[4] Yves, C., Alejandro, O.L., João Carlos, P.D. and Carine, T. (2002) Chagas Disease (American Trypanosomiasis). eMedicine Journal, 3.

[5] Kitonga, P.K. and Daniel, R.L. (2001) Sleeping Sickness (African Trypanosomiasis). eMedicine Journal, 2.

[6] Andreas, K.L. and Gerardo, P. (2010) The Unknown Risk of Vertical Transmission in Sleeping Sickness-A Literature Review. PLOS Neglected Tropical Diseases, 4, e783. http://dx.doi.org/10.1371/journal.pntd.0000783

[7] Behzad, N., Van Tulleken, Ch., Douglas, M. and Chiodini, P.L. (2009) East African Trypanosomiasis in a Pregnant Traveler. Emerging Infectious Diseases, 15. www.cdc.gov/eid

[8] Gundel, H. and Hermann, F. (2002) Review: HIV Infection and Tropical Parasitic Diseases-Deleterious Interactions in Both Directions? Tropical Medicine \& International Health, 7, 479-488. http://dx.doi.org/10.1046/j.1365-3156.2002.00893.x

[9] Stich, A., Abel, P.M. and Krishna, S. (2002) Human African Trypanosomiasis. British Medical Journal, 325, $203-206$. http://dx.doi.org/10.1136/bmj.325.7357.203

[10] World Health Organization Expert Committee (1998) Control and Surveillance of African Trypanosomiasis. Technical Report Series No. 881, 1-114.

[11] CDC (2010) Trypanosomiasis Fact Sheet. www.cdc.gov/ncidod/dpd/parasites

[12] Ikede, B.O., Elhassan, E. and Akpavie, S.O. (1988) Reproductive Disorders in African Trypanosomiasis: A Review. Acta Tropica, 45, 5-10.

[13] Buyst, H. (1973) Pregnancy Complications in Rhodesian Sleeping Sickness. East African Medical Journal, 50, $19-21$.

[14] Sina, G., Testa, G., Triolo, N., Trova, P. and Cramet, B. (1979) [Some New Cases of Congenital Human African Trypanosomiasis (T. gambiense) (Author’s Transl)]. Medecine Tropicale (Mars), 39, 57-63.

[15] (1996) Manson’s Tropical Diseases. 20th Edition, G.C Cook, 1171-1194.

[16] WHO (1995) Model Prescribing Information: Drugs Used in Parasitic Diseases. 2nd Edition, 83-84. http://www.who.int/medicinedocs/index/assoc/h5807e/h5807e

[17] Lowenthal, M.N. (1971) Trypanosomiasis Successfully Treated with Suramin in a Pregnant Woman. Medical Journal of Zambia, 5, 175-178.

[18] Howson, C.P., Harrison, P.F., Hotra, D. and Law, M., Eds. (1996) Committee to Study Female Morbidity and Mortality in Sub-Saharan Africa. Board on International Health, Institute of Medicine, National Academy Press, Washington DC, 216-217. 